E3S Web of Conferences 1, 30001 (2013)

DOI: $10.1051 / \mathrm{e} 3$ sconf/20130130001

(c) Owned by the authors, published by EDP Sciences, 2013

\title{
Human influence on the global mercury cycle: understanding the past and projecting the future
}

\author{
H. M. Amos ${ }^{1}$, D. J. Jacob ${ }^{1, *}$, D. G. Streets ${ }^{2}$ and E. M. Sunderland ${ }^{3, *}$ \\ ${ }^{1}$ Department of Earth and Planetary Sciences, Harvard University, Cambridge, Massachusetts, USA, amos@fas.harvard.edu \\ and djacob@fas.harvard.edu \\ ${ }^{2}$ Decision and Information Sciences Division, Argonne National Laboratory, Argonne, Illinois, USA, dstreets@anl.gov \\ ${ }^{3}$ Department of Environmental Health, Harvard School of Public Health, Boston, Massachusetts, USA, \\ esunder@hsph.harvard.edu \\ *School of Engineering and Applied Sciences, Harvard University, Cambridge, Massachusetts, USA
}

\begin{abstract}
Humans have been releasing mercury $(\mathrm{Hg})$ to the environment since antiquity. Due to the toxicity of $\mathrm{Hg}$, the extent of anthropogenic enrichment is a global health concern. Here we use a global biogeochemical box model to quantify anthropogenic enrichment, investigate the timescales required to remove anthropogenic $\mathrm{Hg}$ from actively cycling reservoirs, and explore future anthropogenic emission scenarios and their impact on $\mathrm{Hg}$ accumulation. By considering the full history of anthropogenic emissions, we find that the global ocean has been substantially enriched by human activity, with implications for exposures of marine fish. Model simulations show anthropogenic $\mathrm{Hg}$ entering surface reservoirs is removed on the order of years. Future emission scenarios that achieve substantial reductions in global anthropogenic $\mathrm{Hg}$ emissions have the dual benefit of decreasing atmospheric deposition and decreasing the pool of legacy $\mathrm{Hg}$ actively cycling in terrestrial and oceanic ecosystems.
\end{abstract}

Key words: mercury, biogeochemical box model, anthropogenic enrichment, legacy mercury

\section{Introduction}

Mercury (Hg) is a naturally occurring element that continuously cycles between the ocean, atmosphere, and land. Humans have been increasing the flux of $\mathrm{Hg}$ from the lithosphere to biologically available reservoirs for millennia through mining, use in products, industry, and fossil fuel combustion (Nriagu, 1994). Due to the toxicity of $\mathrm{Hg}$ and its ubiquity in the environment, the extent of anthropogenic enrichment is a global health concern. Natural $\mathrm{Hg}$ levels are already close to toxicity thresholds (Clarkson and Magos, 2006), leaving little margin for increase without health impacts in humans and wildlife. The United Nations Environment Program (UNEP) is currently negotiating a global treaty to regulate anthropogenic $\mathrm{Hg}$ releases. This requires not only an understanding of how future releases will cycle through the environment over different time horizons, but also of how past releases have contributed to present-day enrichment.
Here we use a global biogeochemical box model that couples surface, intermediate, and deep $\mathrm{Hg}$ reservoirs to better understand how all-time historical emissions contribute to present-day enrichment. We also estimate the timescales of response in the $\mathrm{Hg}$ cycle. Lastly, we explore the response of the global $\mathrm{Hg}$ cycle to different scenarios of future anthropogenic emissions and project the future accumulation of anthropogenic $\mathrm{Hg}$.

\section{Methods}

Here we further develop an 8-compartment biogeochemical box model based on the best-available information on $\mathrm{Hg}$ reservoirs and fluxes from recent global modeling efforts, as described in Streets et al. (2011). Model compartments include: the atmosphere, surface ocean, subsurface waters, deep ocean, fast terrestrial pool, slow soil pool, armored soil pool, and deep mineral reservoir. The representation of the atmosphere is based largely on Holmes et al. (2011), the 


\section{E3S Web of Conferences}

surface ocean on Soerensen et al. (2011), rivers and deep ocean dynamics on Sunderland and Mason (2007), and terrestrial cycling on Smith-Downey et al. (2010). We drive the model with anthropogenic emissions over the period 2000 BC - 2008 AD from Streets et al. (2011).

\section{Results and Discussion}

\section{Timescales}

The time scales required for anthropogenic $\mathrm{Hg}$ to be transferred from the actively cycling surface reservoirs to stable, long-lived reservoirs are directly relevant for policy making. If an anthropogenic perturbation is applied to the atmosphere (e.g. power plan emissions), fast terrestrial reservoir (e.g. agricultural application), or surface ocean (e.g. wastewater), we find that the anthropogenic perturbation is removed from surface reservoirs on the order of months to years. The surface and subsurface ocean respond rapidly to changes is atmospheric deposition, which is important in terms of regulation and its effect on biological exposure.

\section{Present day budget and anthropogenic enrichment}

At present day, we find that the atmosphere, terrestrial, and oceanic global $\mathrm{Hg}$ reservoirs are enriched several-fold relative to natural background.

The magnitude of simulated atmospheric enrichment is within the range of observations from lake sediments (e.g. Biester et al., 2007). A substantial fraction of the $\mathrm{Hg}$ cycling through the present day ocean-atmosphereterrestrial system is legacy $\mathrm{Hg}$.

Legacy $\mathrm{Hg}$ is anthropogenic $\mathrm{Hg}$ that has been previously deposited and reemitted and it plays a central role in the present day global budget. Present day global atmospheric deposition has been estimated to be $\sim 1 / 3$ primary anthropogenic emissions, $1 / 3$ natural emissions, and 1/3 legacy $\mathrm{Hg}$ emissions (Corbitt et al., 2011). This underestimates the contribution of legacy $\mathrm{Hg}$ and overestimate the natural $\mathrm{Hg}$ contribution because it ignores anthropogenic emissions during and before the preindustrial era. We find that legacy $\mathrm{Hg}$ contributes $>50 \%$ to present day global deposition.

Trend analysis from Slemr et al. (2011) suggests that there has been a $20-38 \%$ worldwide decline in atmospheric $\mathrm{Hg}$ between 1996-2009 and they invoke changes in legacy re-emissions as a possible explanation for the observed trends. We cannot reconcile the observed atmospheric trend with our global box model. The release/re-emission of $\mathrm{Hg}$ from products may be important.

\section{Future emission scenarios}

Here we explore four future (2008-2100) scenarios of anthropogenic emissions: (1) constant anthropogenic emissions at the 2008-level; (2) business-as-usual; (3) constant emissions at the 2008-level, then zero anthropogenic emissions after 2020; and (4) constant emissions at the 2008-level, then constant emissions at $50 \%$ of the 2008-level after 2020. Under scenario 2, atmospheric deposition continues to rise even though anthropogenic emissions are held constant due to the increase in legacy Hg. Under scenarios 3 and 4, atmospheric deposition rapidly responds to decreases in anthropogenic emissions and by 2100 deposition in both scenarios is much less than present day deposition. Decreasing anthropogenic emissions has the dual benefit of decreasing atmospheric deposition and as well as decreasing the amount of legacy $\mathrm{Hg}$ actively cycling in surface environments.

\section{Conclusions}

Humans have been releasing $\mathrm{Hg}$ into the environment for millennia (Nriagu, 1994). The accumulation of anthropogenic $\mathrm{Hg}$ in terrestrial and oceanic ecosystems poses a global threat to human health. Here we use a global biogeochemical box model to quantify anthropogenic enrichment, characterize the timescales involved in removing anthropogenic $\mathrm{Hg}$ from the actively cycling surface reservoirs, and investigate future emission scenarios and the potential impact of $\mathrm{Hg}$ accumulation.

We find that at present day all global $\mathrm{Hg}$ reservoirs (surface, intermediate, and deep) are enriched several-fold relative to natural background.

At present, the global $\mathrm{Hg}$ cycle is out of steady state due to the anthropogenic perturbation. Legacy $\mathrm{Hg}$ plays a central role in the present day budget. More than half of global atmospheric deposition is legacy $\mathrm{Hg}$.

Anthropogenic $\mathrm{Hg}$ entering the surface reservoirs is removed on the order of months to years. The surface and intermediate reservoirs respond on the order of years, respectively, to changes in anthropogenic emissions.

We investigate four future anthropogenic emission scenarios (business as usual, constant emissions, and two scenarios with decreasing future emissions). Even if anthropogenic emissions are held constant, atmospheric deposition will increase due to increasing legacy $\mathrm{Hg}$. Reducing future anthropogenic emissions would have the dual benefit of decreasing atmospheric deposition as well as decreasing the pool of legacy $\mathrm{Hg}$ cycling in terrestrial and oceanic ecosystems.

Our model results suggest that the surface and subsurface ocean may be more enriched than previously estimated, suggesting that the margin for decrease is much greater.

\section{Acknowledgements}




\section{ICHMET 2012}

This work was supported by the NSF Atmospheric Chemistry Program. HMA would like to acknowledge support from an NSF graduate fellowship. We would like to thank N. V. Smith-Downey for thoughtful discussion on terrestrial $\mathrm{Hg}$ cycling.

\section{References}

Biester H, Bindler R, Martinez-Cortizas A, Engstrom DR. Modeling the past atmospheric deposition of mercury using natural archives. Environ. Sci. Tech. 2007; 41: 4851-4860.

Clarkson TW, L. Magos. The toxicology of mercury and its chemical compounds. Critical Rev. in Toxic. 2006; 36: 609-662.

Corbitt ES, Jacob DJ, Holmes CD, Streets DG, Sunderland EM. Global source-receptor relationships for mercury deposition under present-day and 2050 emissions scenarios. Environ. Sci. Tech. 2011; 45: 10477-10484.

Holmes CD, Jacob DJ, Corbitt ES, Mao J, Yang X, Talbot R, Slemr F. Global atmospheric model for mercury including oxidation by bromine atoms. Atmos. Chem. Phys. 2010; 10: 12037-12057.

Mason RP, Choi AL, Fitzgerald BC, Hammerschmidt CR, Lamborg $\mathrm{CH}$, Soerensen AL, et al. Mercury biogeochemical cycling in the ocean and policy implications. Environ. Res. 2012; accepted.

Nriagu JO. Mercury pollution from the past mining of gold and silver in the Americas. Sci. Tot. Environ. 1994; 149: 167-181.

Slemr F, Brunke EG, Ebinghaus R, Kuss J. Worldwide trend of atmospheric mercury since 1995. Atmos. Chem. Phys. 2011; 11: 4779-4787.

Smith-Downey NV, Sunderland EM, Jacob DJ. Anthropogenic impacts on global storage and emissions of mercury from terrestrial soils: Insights from a new global model. J. Geophys. Res. 2010; 115: 11 .

Soerensen AL, Sunderland EM, Holmes CD, Jacob DJ, Yantosca RM, Skov H. An improved global model for air-sea exchange of mercury: High concentrations over the North Atlantic. Environ. Sci. Technol. 2010; 44: 8574-8580.

Streets DG, Devane MK, Lu ZF, Bond TC, Sunderland EM, Jacob DJ. All-time releases of mercury to the atmosphere from human activities. Environ. Sci. Technol. 2011; 45: 10485-10491.

Sunderland EM, Mason RP. Human impacts on open ocean mercury concentrations. Glob.. Biogeochem. Cycles 2007; 21: 15. 